\title{
Budgetary Transparency in the European Union: The Role of IPSAS
}

\author{
Sabrina Bellanca
}

Published online: 28 October 2014

(C) International Atlantic Economic Society 2014

\section{JEL E62}

The goal of the International Public Sector Accounting Standards (IPSAS) is to improve the quality of the financial information of public sector entities, to strengthen the transparency of public accounts and to make decision makers more accountable. This modernization seems necessary particularly in the context of the sovereign debt crisis which requires particular attention to accountability and control of public accounts.

The European Union and other supranational organizations are in favor of the implementation of IPSAS. The Council Directive 2011/85/EU of 8 November 2011 on requirements for budgetary frameworks of the member states emphasizes the importance of transparent and reliable information which is necessary to ensure the proper functioning of the European Union. Furthermore this directive is also an opportunity to look at the role of the IPSAS in this regard. So, through public consultation, Eurostat assesses the suitability of the IPSAS for EU member states.

In the literature, accrual accounting is a key element of modern public management. It increases government accounts transparency and provides more complete information. This improves, among other things, government decision making and makes them more responsible. However, the usefulness of accrual accounting in the public sector is sometimes questioned. It is unclear whether accrual accounting is actually appropriate for primarily social or governmental public entities (Christiaens and Rommel, 2008). According to the authors, the conceptual accounting framework for private companies is incompatible with public sector activities. Indeed, characteristics of the public sector require information that sometimes diverges from accounting information required in the private sector. From this perspective, one also wonders whether the IPSAS, based on the principle of accrual accounting, meet the needs of the public sector and whether

S. Bellanca $(\bowtie)$

Warocqué School of Business and Economics, University of Mons - UMONS, 17, Place Warocqué, 7000 Mons, Belgium

e-mail: Sabrina.Bellanca@umons.ac.be 
they are relevant. Public consultation of Eurostat allows us to focus on the opinion of EU member states about the suitability of the IPSAS.

Implementation of the IPSAS is a costly process requiring a lot of time. Moreover, this system is complex and abstract, unlike budgetary accounting which is very easy to use. This complexity makes implementation difficult in small- and medium-sized entities and its abstract nature complicates interpretation, which compromises the objective of international comparability of accounts. It is also worth noting that politicians discuss budgets and not data from balance sheets. But the IPSAS do not focus sharply enough on budgetary/cash accounting. Some say that the IPSAS do not deal with some public sector specificities (social benefits, pension, taxes, historical heritage). Difficulty establishing a link between the IPSAS and ESA (the European System of Accounts) is a major problem. Furthermore, the question of the legitimacy and responsibility of International Federation of Accountants (IFAC) is raised because IFAC currently defines the governance of the IPSAS Board. But for some, the fact that a professional private organization appoints the IPSAS Board members and defines strategies without involvement of member states is problematic. Some people also think that development of public accounting standards by a private organization is problematic. The IPSAS would not meet the needs of member states because of their incomplete and sometimes unsuitable nature.

However, the sovereign debt crisis showed that it was crucial to change the way public sector financial information is collected in Europe. It is necessary to have comparable quality data. Moreover, accounting harmonization between states is a very important point. Indeed, if all EU governments released financial statements according to the same standards, it would be possible to understand and compare the financial situation, debt level and deficit of each country. The objective is also to avoid hiding negative performance and improve financial stability in Europe. By providing a more comprehensive and fair view of the financial position of governments, accrual accounting (one of the principles of the IPSAS) is a tool to reduce uncertainty for rating agencies and other users of financial statements. Harmonized accounting standards would also help investors to compare financial activities of governments. Finally, the IPSAS would reduce the risk of political influence. Transparency and comparability of public accounts would increase government accountability and improve decisionmaking.

General agreement does not exist for the usefulness of the IPSAS for EU member states. There is opposition among professional association standardization bodies, auditing and accounting companies which are in favor of the IPSAS, and ministries and other public organizations which are not in favor of the IPSAS. Accrual accounting may be sufficient to meet the transparency and performance needs of the public sector. It may not be necessary to define a unique accounting framework. Therefore, whether international accounting harmonization is necessary is unclear. Perhaps a European accounting framework should be created with the involvement of the member states. 